\title{
O Papel de Intervenções Específicas na Compreensão da Criança sobre Proporção
}

\author{
Alina GalvãoSpinillo 12 \\ UniversidadeFederaldePemambuco
}

\begin{abstract}
Resumo
Pesquisas anteriores mostraram que crianças usam espontaneamente a estratégia de 'metade' para fazerjulgamentos proporcionais. O presente estudo examina a possibilidade de que crianças possam aprender sobre proporções, usando esta estratégia de maneira sistemática, transferindo sua aplicação para outras tarefas de proporção consideradas difíceis. Adotando-se um planejamento experimental envolvendo pré, pós-teste e uma intervenção, 180 crianças de 6 a 8 anos foram divididas em três grupos: um em que apenas realizavam uma tarefa de proporção, um grupo controle e um grupo experimental. 0 desempenho no pós-teste foi melhor do que no pré-teste apenas para as crianças que receberam a intervenção, as quais superavam as dificuldades iniciais; estas foram mais bem sucedidas no pós-teste do que as crianças dos demais grupos. Concluiu-se que crianças podem ser ensinadas a fazerjulgamentos proporcionais, sendo a estratégia de 'metade' um referencial importante que auxilia a lidar com as quantidades e as relações cruciais ao raciocínio proporcional.

Palavras-chave: Intervenção; estratégia de 'metade'; proporção; crianças.
\end{abstract}

\section{The Role Played by Intervention on Children's Understanding of Proportion}

\begin{abstract}
This study examines the possibility that children can leam how to make proportional judgements by using the half' strategy in a systematic way, and also to transfer its application to another proportional task which proved to be a difficult one. The experimental design consisted of a pre-test, a post-test, and a training procedure. One hundred and eighty children aged 6 to 8 years old were divided into three groups: task group, control group and training group. Only children who received the intervention did significantly better in the post-test than in the pre-test, and they were more successful in the post-test than children in the other groups. They were able to overcome their initial difficulties after training. The conclusion was that children can be taught how to make proportional judgements and that the 'half' strategy helps them to deal with the quantities and relations crucial to proportional reasoning.

Keywords: Intervention; half' strategy; proportion; children.
\end{abstract}

O conceito de proporção tem sido investigado através de uma vaniedade de tarefas que, de modo geral, podem ser agrupadas em duas classes de problemas: tarefas de incógnita e tarefas de comparação (Toumiaire \& Pulos 1985). Além dos tipos de problemas, as tarefas utilizadas variam em função das dimensões envolvidas: complementares e não-complementares. Dimensões complementares referemse a quantidades (contínuas ou discretas) que são partesque, juntas, formam um mesmo todo; enquanto dimensõesnãocomplementares são quantidades que não constituem um mesmo todo. A tarefa de quantificação de probabilidades de Piaget e Inhelder (1975) envolve dimensões complementares (cartas com cruz vs. cartas sem cruz que

\footnotetext{
1 Endereço para comespondência: Universidade Federal de Pemambuco, Pós-Graduação em Psicologia, $\mathrm{CFCH}-8^{\circ}$ andar, Cidade Universitária, 50670-901, Recife, PE. Fone: (81) 32718272/ Fax: (81) 32711843. E-mail: spin@npd.ufpe.br

2 Esta pesquisa recebeu apoio do Conselho Nacional de Desenvolvimento Científico e Tecnológico (CNPq). Agradecimentos especiais a Ana Paula Medeiros, Flávia Veras, Rossana Barreiras e Silvana Pimentel que realizaram as entrevistas com as crianças e auxiliaram na análise dos dados.
}

formam um mesmo todo - conjunto de cartas), e a tarefa da balança de Inheldere Piaget (1976) adota dimensões não-complementares (peso vs. distância). Spinillo (1992,1993,1997b) ressalta a importância da distinção entre dimensões complementares e dimensões não complementares para se compreender a natureza das dificuldades experimentadas porcrianças ao resolvertarefas de proporção.

Apesar desta diversidade de formas de investigar este conceito, os estudiosos concordam que o raciocínio proporcional requer: a) reconhecer a equivalência entre situações distintas; b) pensarem temos relativos e não em temos absolutos; e c) estabelecer relações entre relações, i.e., estabelecer relações de segunda-ordem que ligam duas ou mais relações de primeira-ordem. Estes aspectos são o ceme do raciocínio proporcional, em especial as relações de primeira e de segunda-ordem.

O problema de comparação proposto por Noelting (1980a,1980b), conhecido como a tarefa do suco de laranja, é um excelente exemplo para ilustraro que vem a ser as relações de primeira e de segunda-ordem. Neste estudo, o seguinte problema é apresentado às crianças: 
“Uma jarra contém uma bebida preparada com dois copos de concentrado de laranja e dois copos de água. Uma outra jarra contém dois copos de concentrado de laranja e dois copos de água. Qual delas tem o gosto mais forte de laranja, ou elas têm o mesmo gosto?' Para resolver este problema, a criança pode, inicialmente, estabelecer uma relação entre o número de copos de concentrado de laranja e de água em cada jarra. As relações entre concentrado vs. água em cada jarra (2:2 e 3:3) são as relações de primeira-ordem. A relação de segunda ordem consiste em comparar essas duas relações para verificar se são equivalentes ou não (2:2 vs. 3:3).

Segundo alguns pesquisadores, em especial Piagete colaboradores (Inhelder \& Piaget, 1976; Piaget \& Inhelder, 1975), o conceito de proporção é uma aquisição tardia própria das operações formais; e apontam como a principal causa das dificuldades das crianças a incapacidade em estabelecer as relações de segunda-ordem. Sem minimizar a importância dessas relações para o pensamento proporcional, énecessánio, entretanto, considerar, também, o papel crucial desempenhado pelas relações de primeiraordem que são o ponto de partida das relações de segundaordem.

A partir de uma ampla revisão da literatura sobre 0 raciocínio proporcional em crianças verificou-se que Müller $(1978,1979)$ foi o primeiro pesquisador cujo estudo permitiu uma reflexão acurada sobre a conexão entre as relações de primeira e de segunda-ordem. Investigando crianças de 7 a 10 anos, Müller (1979) contrastou o efeito de dois tipos de intervenção sobre a habilidade em fazer julgamentos proporcionais. Além de um grupo controle, dois gnupos experimentais foram comparados: um grupo recebia uma intervenção baseada em feedback, em que as crianças eram informadas sobre se suas escolhas eram corretas ou incorretas; e um outro grupo recebia uma intervenção baseada em explicações a respeito do tipo de raciocínio utilizado pela criança (se em termos relativos ou se em termos absolutos). Os dados mostraram não haver diferenças significativas entre os dois grupos experimentais e o grupo controle no pré-teste. Entretanto, as crianças do grupo de explicação foram mais bem sucedidas que as dos outros dois grupos no pós-teste. A conclusão foi que oferecer explicações relacionadas aos princípios subjacentes ao conceito de proporção é uma forma mais efetiva de desenvolver a compreensão sobre este conceito do que meramente fomecer feedback, e que mesmo as crianças mais novas se beneficiavam deste tipo de procedimento.

Um outro estudo de intervenção sobre proporção, é a pesquisa de Sieglere Vago (1978). Os autores levantaram a possibilidade de que a principal razão das crianças não adotarem uma regra de proporcionalidade em seus julgamentos devia-se à impossibilidade em integrar as variáveis relevantes da tarefa em uma única estratégia. A tendência das crianças, como documentado na literatura, é concentrar-se apenas em uma das variáveis ao emitir seus julgamentos. Por exemplo, na tarefa de quantificação de probabilidades de Piagete Inhelder (1975), as crianças atentavam para o número de cartas com cruz, ignorando o papel desempenhado pelas cartas sem cruz; na tarefa do suco de laranja de Noelting (1980a, 1980b) as crianças consideravam o número de copos de concentrado de laranja, desconsiderando o número de copos de água; e na tarefa dos recipientes com água de Bruner e Kenney (1966) consideravam a água, ignorando o espaço vazio dos recipientes.

Usando uma versão da tarefa de Bruner e Kenney (1966), Sieglere Vago (1978) realizaram uma intervenção que explicitamente encorajava as crianças ( 7 a 10 anos) a combinar as variáveis relevantes (água e espaço vazio) em uma única estratégia. Esta instrução, de fato, favorecia o estabelecimento de julgamentos proporcionais que expressavam a integração dessas duas variáveis em uma única estratégia.

Colocando-se em perspectiva o estudo de Sieglere Vago (1978) e o de Müller (1979), dois pontos surgem como importantes para reflexão. O primeiro ponto é saber que aspecto propiciou o sucesso nesses dois tipos de intervenção. É possível que o sucesso tenha decomido do fato de que o examinador chamava a atenção das crianças para as relações de primeira-ordem. Em ambas as intervenções, o examinador tomava as relações de primeira-ordem mais salientes e mais acessíveis para a criança, ensinando-a a tratar as relações de primeiraordem em termos parte-parte; o que tornava possível estabelecer as relações de segunda-ordem 1. Esta análise, entretanto, não foi conduzida pelos autores dessas investigações, mas encontra respaldo na perspectiva de outros estudiosos, como discutido adiante. O segundo ponto a ser considerado é se as intervenções propostas ensinaram proporção pela primeira vez às crianças ou se elasjá possuíam alguma noção inicial sobre este conceito, ainda que de forma intuitiva.

Existem evidências de que crianças de 6 anos possuem um conhecimento intuitivo sobre proporção e que as causas das dificuldades em resolver tarefas de proporção residem, muitas vezes, no estabelecimento das relações de primeira-ordem e não, necessariamente nas relações de segunda-ordem.

Spinillo e Bryant $(1991,1999)$ realizaram uma séne de experimentos sobre proporção em crianças de 4 a 8 anos de idade, cujos resultados consistentemente mostraram 
que desde os 6 anos as crianças apresentam noções iniciais sobre proporção, estabelecendo relações parte-parte (razão), ao invés de relações parte-todo (fração) para decidirem a respeito da equivalência entre quantidades contínuas e discretas. As relações parte-parte envolviam o uso da 'metade' como ponto de referência ('mais que metade', 'menos que metade', 'igual à metade'), estratégia esta que auxiliava a criança a fazer julgamentos proporcionais. Os autores concluíram que a noção de 'metade' desempenha papel importante na compreensão inicial sobre proporção.

Um outro dado importante denivado dessas pesquisas é a distinção entre as relações de primeira e de segundaordem. Tomando esta distinção como base para a análise de diversos protocolos de crianças resolvendo tarefas de proporção disponibilizados na literatura, Spinillo e Bryant verificaram que as dificuldades das crianças não residem nas relações de segunda-ordem, como sugenido por Piaget e colaboradores; mas com as relações de primeira-ordem. Se estas são fáceis de serem compreendidas, as crianças podem, então, estabelecer as relações de segunda-ordem.

Mas, quaisas relações de primeira-ordem que as crianças estabelecem sem dificuldades desde cedo?De acordo com a análise conduzida por Spinillo (1993, 1994b, 1997b; Spinillo \& Bryant, 1991), as crianças compreendem relações parteparte antes de compreenderem relações parte-todo. As relações parte-parte têm ongem em relações simples como 'mais/maior do que', menos/menor do que'e igual a'. Estas comparações estão em estreita relação com a compreensão de códigos relativos, aquisição esta que antecede o domínio dos códigos absolutos que se referem à quantificação numérica precisa (Bryant, 1974). Essas aquisições iniciais entram em jogo durante a resolução de tarefas que envolvem conceitos relacionais complexos como a proporção e a probabilidade (Correa, Spinillo, Brito \&Moro, 1998; Spinillo, 1997a).

A idéia de que as crianças preferencialmente representam tarefas de proporção em termos parte-parte encontra respaldo nos estudos de Resnick e Singer (Resnick \& Singer, 1993; Singer, Kohn \& Resnick, 1997; Singer \& Resnick, 1992). A perspectiva teónica dessas autoras a respeito das origens intuitivas dos conceitos relacionais envolve esquemas por elas denominados protoquantitativos. Estes esquemas permitem que a criança raciocine e estabeleça relações sem a necessidade de quantificá-las numenicamente. Mais tarde, ao longo do desenvolvimento, este conhecimento é transformado em formas de representação quantificadas e matematicamente exatas. Julgamentos protoquantitativos, embora não numéricos, podem incluir os princípios essenciais de um conceito; no caso da proporção, esses princípios referem-se às relações que precisam ser estabelecidas quer de forma numénica ou não numénica.
A partir dessas discussões, conclui-se que as crianças resolvem tarefas de proporção em que as relações de primeira-ordem requerem comparações parte-parte; porém, têm dificuldades com tarefas em que as relações de primeira-ordem requerem comparações parte-todo.

Um exemplo disso é o estudo clássico de Brunere Kenney (1966) em que crianças entre 5 e 11 anos eram solicitadas a determinar qual dentre dois recipientes com água era o mais cheio ou se ambos estavam igualmente cheios. Recipientes de variados tamanhos e com quantidades diferentes de água eram apresentados aos pares. Nesta tarefa, as relações de primeira-ordem (em cada recipiente) podiam ser estabelecidas de duas maneiras: a) entre o espaço ocupado com água e o volume total do recipiente (relação parte-todo); ou b) entre o espaço ocupado com água e o espaço vazio (relação parte-parte). A relação de segunda-ordem, por sua vez, consistia em comparar as relações de primeira-ordem entre si: a) água-volume total em cada recipiente (duas relações parte-todo); ou b) água-espaço vazio em cada recipiente (duas relações parte-parte).

A principal dificuldade das crianças era lidar com comparações entre dois recipientes de tamanhos diferentes e com volumes diferentes de água, mas que estavam cheios até a metade. As crianças não reconheciam a equivalência entre os dois recipientes, estabelecendo julgamentos absolutos ao invés de julgamentos relativos. De modo geral, neste e em outros itens da tarefa, as crianças faziam julgamentos com base no nível de água ('o recipiente mais cheio é aquele com nível de água mais alto') ou com base no volume de água ('o recipiente mais cheio é aquele que tem mais água')

Uma explicação para esta dificuldade é que a pergunta endereçadaà criança ("Qual o recipiente mais cheio ou estão ambos igualmente cheios?') e a própria noção de 'cheio' requeriam o estabelecimento de relações parte-todo para a solução da tarefa (água vs. volume total do recipiente). É possível que as dificuldades em fazer julgamentos proporcionais tenham decomido da dificuldade da criança em lidar com as difíceis relações de primeira-ordem do tipo parte-todo. Seniam as crianças mais bem sucedidas se as relações de primeira-ordem pudessem ser estabelecidas em termos parte-parte (água vs. espaço vazio) ao invés de parte-todo (água vs. volume total do recipiente)?Elas ainda teriam dificuldades em reconhecer a equivalência entre dois recipientes de diferentes tamanhos igualmente cheios até a metade?

Diante das evidências obtidas por Spinillo e Bryant(1991, 1999) a respeito do referencial de 'metade', toma-se importante investigar a possibilidade de que, usando comparações parte-parte (água vs. espaço vazio), as crianças 
seriam capazes de fazerjulgamentos proporcionais ('mais que metade com água e menos que metade sem água', e 'metade com água e metade sem água'). Em taisjulgamentos o volume total dos recipientes (o todo) seria imelevante, não havendo necessidade de relacionaro espaço ocupado com água ao volume total do recipiente (comparações partetodo).

Esta hipótese foi testada na presente investigação através de um estudo de intervenção voltado para encorajar a criançaa: a) adotar, sistematicamente, a estratégia de 'metade' para determinar a equivalência ou não equivalência entre situações representadas por quantidades contínuas; e b) refletir e lidar, de maneira explícita, com as relações de primeira-ordem em uma tarefa de proporção.

O presente estudo teve, ainda, por objetivo avaliara eficácia de uma intervenção específica sobre a proporção em crianças que ainda não haviam sido formalmente instruídas sobre este conceito no contexto escolar. Procurouse, também, investigar se as crianças aplicariam 0 conhecimento adquindo em uma dada situação a uma outra situação diferente e mais complexa do que aquela usada durante a intervenção. Note-se, por exemplo, que os estudos de Müller(1979) e de Sieglere Vago (1978) adotavam tanto no pré-teste como no pós-teste a mesma tarefa utilizada na intervenção. Para examinar este aspecto relacionado à transferência, utilizou-se uma tarefa no pré e no pós-teste que era diferente daquela apresentada durante a intervenção.

Em função desta hipótese e dos objetivos propostos, algumas predições foram feitas sobre o desempenho das crianças que receberam a intervenção: a) um desempenho superior após a intervenção, comparando-se para isso os resultados do pré-teste com os do pós-teste no grupo experimental; eb) um desempenho no pós-teste superior ao das crianças que não receberam a intervenção, comparando-se para isto os resultados entre o grupo experimental e os demais. Importante mencionar que estas mesmas predições foram feitas em relação ao estabelecimento de julgamentosproporcionais: estes seniam maisfreqüentes no pós-teste realizado pelas crianças do gnupo experimental.

\section{Método}

\section{Participantes}

Cento e oitenta crianças de classe média igualmente divididas em três gnupos etánios: 6 anos ( $m=6 a$ 4m), 7 anos $(m=7 a$ 6m) e 8 anos $(m=8 a$ e $4 m)$. Elas eram alunas de alfabetização, primeira e segunda séries do ensino fundamental de escolas particulares na cidade do Recife; não havendo sido fomalmente instruídas sobre proporção no contexto escolar.

\section{Procedimento e Planejamento Experimental}

Apósum pré-teste (versão da tarefa de Bruner \& Kenney, 1966 apresentada na Figura 1), aplicado na primeira sessão, 60 crianças em cada idade foram igualmente divididas em três grupos:

Grupo 1 (tarefa): as crianças resolviam uma tarefa de proporção (versão da tarefa de Spinillo \& Bryant, 1991, apresentada na Figura 2) sem receber nenhum tipo de intervenção, sendo aplicado, então, um pós-teste que consistia na mesma tarefa apresentada no pré-teste. Este grupo foi incluído por serimportante examinar se o mero contato com a tarefa em si contribuiria para um melhor desempenho no pós-teste.

Grupo 2 (controle): as crianças realizavam apenas o pré e o pós-teste.

Grupo 3 (experimental): as crianças recebiam uma intervenção específica durante a resolução de uma tarefa de proporção (a mesma apresentada ao Grupo 1). A tarefa usada durante a intervenção era diferente daquela adotada no pré e no pós-teste. Com isso pretendeu-se examinar se as crianças transfeniriam o que foi aprendido durante a intervenção a uma outra situação apresentada no pós-teste.

Cada criança era entrevistada individualmente em duas ou três sessões por um mesmo examinador, com um intervalo de aproximadamente uma semana entre cada sessão. Para as crianças do Grupo 2 (controle) houve um período de duas semanas entre sessões para que 0 intervalo entre pré e pós-teste fosse o mesmo para toda a amostra. As sessões foram gravadas em áudio e transcritas o mais literalmente possível, incluindo-se o registro de todo o comportamento não verbal do entrevistado.

\section{Astarefas}

A tarefa no pré e no pós-teste consistia em comparações entre pares de recipientes de diferentes tamanhos, com água em diferentes volumes e níveis. A criança era solicitada a deteminar qual dos dois recipientes estava mais cheio ou se ambos estavamigualmente cheios, justificando suas respostas.

Um recipiente em cada par estava $1 / 4$ cheio, $1 / 2$ cheio, $3 / 4$ cheio ou completamente cheio. Situações de equivalência foram exploradas entre recipientes que estavam igualmente cheios (mesma proporção: $1 / 2$ vs. 1/2; Cheio vs. Cheio). Em outras ocasiões os recipientes não estavam em equivalência (proporção diferente: $1 / 2$ vs. $1 / 4$; $1 / 2$ Vs. $3 / 4 ; 1 / 4$ Vs. 3/4). Um total de 18 itens foi apresentado, os quais foram igualmente divididos em seis diferentes tipos, como mostra a Figura 1, na qual consta um exemplo de cada tipo de item. 


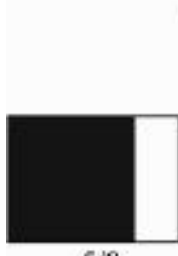

$5 / 8$
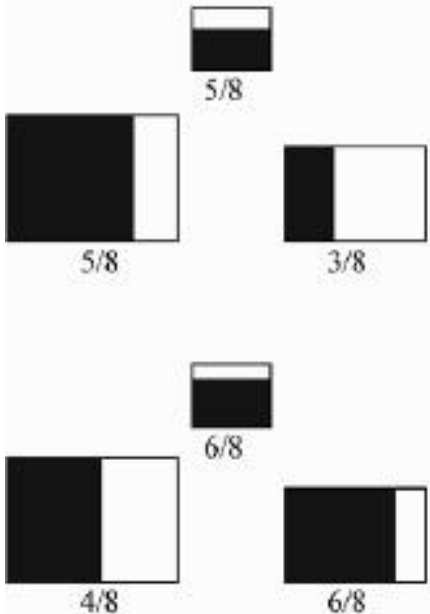

$6 / 8$

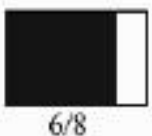

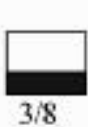

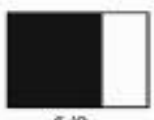

$5 / 8$

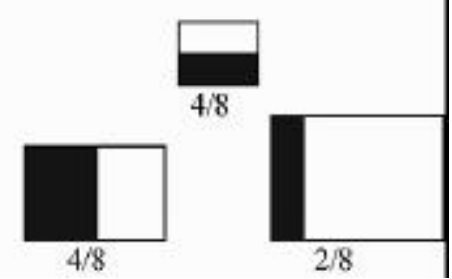

Figura 1. Exemplos de alguns itens apresentados durante a intervenção.

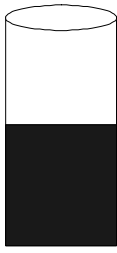

Item Tipo 1
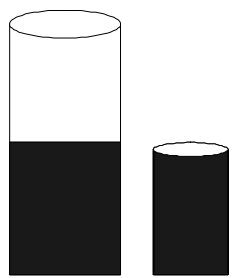

Item Tipo 3

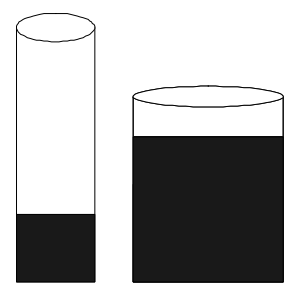

Item Tipo 5

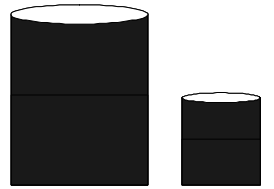

Item Tipo 2
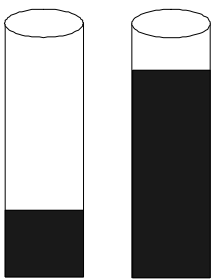

Item Tipo 4

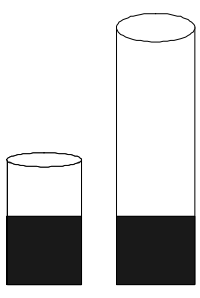

Item Tipo 6

Figura 2. Exemplos de alguns itens na tarefa no pré-teste e no pós-teste.

Na tarefa apresentada ao Grupo 1 (tarefa) e ao Grupo 3 (experimental) as crianças eram solicitadas a julgar qual dentre dois retângulos de papel $(12 \mathrm{~cm}$ x $16 \mathrm{~cm} \mathrm{e} 8 \mathrm{~cm} \mathrm{x}$ $12 \mathrm{~cm}$ ) divididos em uma parte preta e outra branca comespondia a um pequeno retângulo de papel $(4 \mathrm{~cm} \mathrm{x}$ $8 \mathrm{~cm})$, também dividido em uma parte preta e outra branca. A parte preta em cada retângulo variava: 2/8 preto, $3 / 8$ preto, $4 / 8$ preto, $5 / 8$ preto e $6 / 8$ preto. Os retângulos apresentados em cada item poderiam ter. a) igualdade das partes; b) parte preta maior que a branca; $\mathrm{e}$ c) parte preta menor que a branca. Foram aplicados 12 itens ao todo, alguns deles ilustrados na Figura 2. 
Em algunsitens o retângulo pequeno (modelo) estava verticalmente seccionado; enquanto os retângulos grandes (altemativas) estavam horizontalmente seccionados. Em outros itens ocorria o oposto: o modelo estava horizontalmente seccionado e as altemativas verticalmente seccionadas.

A tarefa no pré e no pós-teste era mais complexa do que a tarefa utilizada na intervenção. Apesar de diferentes, as duas tarefas eram comparáveis quanto a determinados aspectos, pois ambas: a) eram tarefas de comparação; b) envolviam dimensões complementares; c) podiam ser solucionadas através de comparações parte-parte ou partetodo; d) envolviam quantidadescontinuas; ee) não requeniam quantificações numéricas precisas, podendo serresolvidas por estimativas. Estas similanidades permitiam que alguma transferência ocorresse de uma tarefa para outra, caso as crianças do grupo experimental se beneficiassem da intervenção fomecida.

\section{Aintervenção no grupo experimental}

Em linhas gerais, a intervenção proposta pode ser definida como de natureza tutorada que se caracteriza pela instrução explícita de algo, em que o adulto desempenha papel ativo na tentativa de promover formas mais sofisticadas de pensamento (Spinillo, 1999). A criança, por suavez, como pode a princípio parecer, não atua de maneira passiva diante das ações e verbalizações do adulto. Ao contránio, ela é constantemente solicitada e desafiada a pensar sobre seu pensamento, sobre as intervenções do adulto e sobre as características da situação que são colocadas em destaque. A intervenção oferecida tem porbase um processo cognitivo da maiorimportância para o desenvolvimento e para a aprendizagem: a metacognição. Como mencionado por Spinillo (1999, p. 69), a metacognição, em situações de intervenção, leva a criança a "(...) pensar sobre suas formas de raciocinare sobre as caracteństicas e princípios essenciais que regem o conceito ou a habilidade que se deseja desenvolver." Este processo cognitivo envolve a reflexão e aconsciência sobre o que se está fazendo, dizendo e pensando em uma deteminada situação. Situações mediadas porum adulto são mais propiciadoras da ativação deste processo do que situações baseadas na autodescoberta.

A intervenção, apresentada em uma única sessão, durou cerca de 40 minutose tinha por objetivo levara criança a: a) usarsistematicamente o referencial de 'metade' para julgara equivalência e a não equivalência entre o modelo e as altemativas; eb) discriminare explicitar as relações de primeira e de segunda-ordem envolvidas na solução da tarefa.

Para isto, o examinador, em seu diálogo com a criança, fomecia feedback, lançava desafios (situações de conflito e contra-argumentos), fomecia e solicitava explicações. As intervenções concentravam-se nos invariantes próprios do raciocínio proporcional: as relações de primeira-ordem no interior de cada retângulo (preto vs. branco) e nas relações de segunda-ordem (preto vs. branco nas altemativas e no modelo). Essas relações eram estabelecidas em temos de razões preto:branco, em que o referencial de 'metade' era explicitamente enfatizado como um ponto de referência para identificar, por estimativa, a equivalência e a não equivalência entre o modelo e as altemativas.

As passagens a seguir ilustram a intervenção oferecida, tomando como exemplos situações em que a criança fazia escolhas cometas e situações em que fazia escolhas incometas em seusjulgamentos 2:

\section{Escolha correta}

\section{Exemplo 1}

Item: $5 / 8$ preto (modelo) 5/8 preto vs. $3 / 8$ preto (altemativas)

E (examinador) - Qual desses retângulos (alternativas) combina com o pequeno (modelo)?

C (criança) - Este (altemativa 5/8).

E- Certo! Porque você escolheu esse?

C - Porque ele tem uma parte preta grande e o retângulo pequeno também tem uma parte preta grande.

E- Você escolheu o retângulo com mais preto que branco como tem nesse daqui também (modelo).

C - Foi. Grande (aponta para a parte preta no modelo) e grande (aponta para a parte preta na altemativa 5/8)

E- E porque não podia ser esse outro (aponta altemativa $3 / 8)$ ?

$\mathrm{C}$ - Pode nada! Porque ele tem mais branco que preto.

E- E daí?Me explica melhor.

C- $O$ pequeno (modelo) e esse (altemativa 5/8), os dois têm mais preto que branco. E esse (alternativa 3/8) tem mais branco que preto.

E- É verdade, não podia ser esse (altemativa 3/8) porque nele tem mais branco que preto e assim não combina com 0 modelo. $O$ pequeno (modelo) tem mais preto que branco.

C - Então eu estou certa, não estou?

E - Está sim. Preste atenção que eu vou dar uma pista: No modelo enesse retângulo (altemativa 5/8) tem mais da metade preto e menos da metade branco. Por isso os dois estão combinando.

C- Metade fica no meio (aponta para a metade em cada um dos três retângulos sobre a mesa).

E- É, fica sim.

\section{Exemplo 2}

Item: 4/8 preto (modelo) 4/8 preto vs. $2 / 8$ preto (altemativas)

E- Qual desses retângulos (altemativas) combina com o pequeno (modelo)?

C - (aponta altemativa 4/8).

E- Como descobriu? 
C- Os dois têm preto e branco igual.

E- E por que não podia ser este (altemativa 2/8)?

C- Ainesse de cá (altemativa 4/8) tem metade e metade de cada cor, feito que tem no pequeno (modelo).

E- É. Não podia ser este (altemativa 2/8) de jeito nenhum, porque ele tem mais branco que preto.

C- Eles não combinam porque são diferentes.

E- Diferentes como?Me explica como é isso.

$\mathrm{C}$ - Aqui (modelo) as partes são metade e metade; e nesse (altemativa 2/8) as partes não são iguais. Tem mais branco que preto.

E- Agora entendi. Aqui (altemativa 2/8) tem mais da metade branco emenos da metade preto.

C - É.

E- Você pode usar uma pista para descobrir. Vou ensinar estapista. Vocêolhaonde que fica ametade em cada retângulo (mostra). Ai dá prá ver que esse pequeno (modelo) e esse (altemativa 4/8) combinam porque os dois têm metade branco e metade preto. $\mathrm{O}$ outro (altemativa 2/8) é menos que metade preto e mais que metade branco. Entendeu?Vou mostraroutro prá verse você descobre, usando esta pista da metade.

Note-se que mesmo quando a escolha da criança era correta, o examinador salientava o referencial de 'metade' e as comparações parte-parte nas relações de primeiraordem. Além disso, eram fomecidas explicações sobre as razões porque uma altemativa era correta e a outra incorreta, auxiliando a criança a verbalizar de maneira mais clara sua forma de pensar.

\section{Escolhaincorreta}

\section{Exemplo3}

Item: $5 / 8$ preto (modelo) $5 / 8$ preto vs. $3 / 8$ preto (altemativas)

E- Eagora, qual desses retângulos (altemativas) combina com o pequeno (modelo)?

C - Este (3/8).

E- Errou. Eles não combinam não.

C - Combina sim.

E- Então me explica como você descobriu.

C- Eles combinam porque eles têm a mesma quantidade de preto (aponta para o a parte preta do modelo e para a parte preta da altemativa $3 / 8$ ). A parte preta aqui (modelo) é do mesmo tanto que essa parte preta aqui (altemativa 3/8).

E- É, pode serque a quantidade nos dois seja a mesma, mas os dois retângulos não combinam de jeito nenhum não. Sabe uma foto?Uma foto sua é bem menorque você. Évocê na foto, mas o tamanho seu na foto é bem menor do que o seu tamanho de verdade.

C - Tá.

E- Numa foto tudo é o mesmo, mas menor. Assim é aqui com esses retângulos.

C- (silêncio)
E- Vou daruma pista para você descobrir sempre qual éa resposta certa. Quersaber?

C-(faz que sim com a cabeça)

E- Vamos fazer com a metade. Vamos pensar onde fica a metade de cada retângulo. Nesse (modelo) tem mais que metade preto e menos que metade branco. Olha prá esse de cá (altemativa 5/8): esse retângulo também tem mais que 'metade' preto e menos que 'metade' branco. Agora, olha prá esse que você escolheu (altemativa 3/8). Ele tem mais da metade branco e menos da metade preto. Eles (modelo e altemativa 5/8) parecem que não combinam porque um é de tamanho grande e outro de tamanho pequeno (modelo). Mas, mesmo assim eles combinam. A gente vê isso quando a gente compara o preto com o branco dentro do retângulo. Entendeu?

C-Hum hum.

E - Você não tava olhando para a parte preta e para a parte branca dos retângulos.

C - Ah!Era isso! Eu tava pensando só na parte preta de cada um. Preto com preto.

E - Isso ai. Esse era o seu erro. Você tem que comparar ... (criançaintemompe)

C - Já sei. Já entendi. Eu tenho que olhar pro preto e pro branco nos três (aponta modelo e altemativas). Ai depois eu vejo qual que tá igual a esse (modelo).

E - Certo.

C - Então é esse (altemativa 5/8). Posso mudar, não posso?

E- Pode. Você pode mudarde idéia quantas vezes quiser. $\mathrm{O}$

importante é explicar como está pensando, como está comparando dentro de cada retângulo e depois um com 0 outro (retângulo).

C - Então é esse (altemativa 5/8).

E - É.

C - Este (altemativa 5/8) combina com esse (modelo) por causa que eles são iguais de preto para branco. Eles têm mais preto que branco.

E- E porque foi que você emou da primeira vez?

C - Eu agorajá sei fazer. Acho a metade. Ai vejo se uma é maiorou menorque a outra (refere-se às partes) e pronto. Aí tá fácil.

E - Certo. Ai depois de olhar para cada parte dentro do retângulo, faz o quê para descobrir?

C - Vejo qual que vai combinar. Assim, se tem preto e branco do mesmo jeito que no pequeno.

\section{Escolha correta, porém usando julgamento não proporcional}

Exemplo4

Item: $6 / 8$ preto (modelo) 4/8 preto vs. $6 / 8$ preto (altemativas)

E-E agora, qual desse dois (altemativas) combina com 0 pequeno (modelo)?

C - (aponta altemativa 6/8)

E- Como descobriu? 
C- Eles parecem do mesmo tamanho. O branco tá igual, tá feito uma tira.

E- Tá certo, é esse mesmo (altemativa 6/8). Mas você emou no jeito de pensar.

C- (silêncio).

E- Sabe porque?

C- Sei não.

E- Vamos olharaqui no retângulo pequeno (modelo). Ele tem mais preto que branco. Mais da metade preto e menos da metade branco. Nesse que você escolheu (altemativa 6/8) também tem mais da metade preto e menos da metade branco. No outro (altemativa 4/8) não podia serporque tem metade preto e metade branco.

C- Émesmo.

E- Só que você não pensou assim, você ficou olhando só para a quantidade de branco. Tem que olharpro preto e pro branco em cada retângulo. Olhando pro preto e pro branco como é esse (modelo)?

C- Mais da metade com preto e menos da metade branco.

Que nem esse (altemativa 6/8)

E- Certo. E como é nesse de cá (altemativa 4/8)?

C-É metade e metade certinho.

E- Olhando na metade é sempre mais fácil de descobrir, não é?

C-É.

\section{Resultados}

Os dados no pré-teste e no pós-teste na tarefa dos recipientes foram analisados em função do número de acertos e das justificativas em cada item. Cada um desses aspectos é tratado a seguir.

\section{O desempenho das crianças}

O teste Kruskall-Wallis examinou, no pré-teste e no pós-teste separadamente, o possível efeito da idade sobre o desempenho das crianças. Como mostra a Tabela 1, a idade não foi fator determinante do desempenho quer no pré-teste $(\mathrm{p}=0,2633)$ quer no pós-teste $(\mathrm{p}=0,1513)$.

Diferenças significativas também não foram detectadas ao se compararas idades duas a duas ( 6 anos vs. 7 anos; 6 anos vs. 8 anos; 7 anos vs. 8 anos) através do Ude MannWhitney tanto no pré-teste como no pós-teste, isoladamente. Diferentemente da idade, a intervenção, no entanto, teve um efeito expressivo sobre o desempenho, querno geral (Tabela 2) quer em cada idade entre as crianças do expenimental (Tabela 1).

O teste Ude Mann-Whitney, aplicado aos dados no pré-teste e no pós-teste separadamente, mostrou que no pré-teste, o número de respostas corretas não diferia significativamente entre os grupos (Grupo 1 vs. Grupo 2: $\mathrm{p}=0,7109$; Grupo 2 vs. Grupo 3: $p=0,4134$; e Grupo 1 vs. Grupo 3: $p=0,6002)$. Por outro lado, no pós-teste, as crianças do Grupo 3 (experimental) tiveram um desempenho superior quando comparadas às crianças dos outros dois grupos (Grupo1 vs. Grupo 3: $\mathrm{p} \varangle 0,0001$; Grupo 2 vs. Grupo 3: p <0,0001), o mesmo não ocomendo ao se comparar o Grupo 1 (tarefa) e o Grupo

Tabela 1

Média deAcertos(máximo: 18)

\begin{tabular}{ccccccc}
\hline & \multicolumn{2}{c}{ 6anos } & \multicolumn{2}{c}{7 anos } & \multicolumn{2}{c}{8 anos } \\
& Pré-teste & Pós-teste & Pré-teste & Pós-teste & Pré-teste & Pós-teste \\
\hline $\begin{array}{c}\text { Grupo 1 } \\
\text { (tarefa) }\end{array}$ & 9,7 & 9,6 & 10,8 & 12 & 9,7 & 9,5 \\
$\begin{array}{c}\text { Grupo 2 } \\
\text { (controle) }\end{array}$ & 10,8 & 11 & 8,7 & 9,2 & 10,4 & 11,6 \\
$\begin{array}{c}\text { Grupo 3 } \\
\text { (experimental) }\end{array}$ & 9,2 & 13,7 & 9,1 & 16,1 & 10,7 & 15,2 \\
\hline Média & 9,9 & 11,4 & 9,5 & 12,4 & 10,2 & 12,1 \\
\hline
\end{tabular}

Tabela 2

Média deAcertos(máximo:18)

\begin{tabular}{cccc}
\hline & Grupo 1 & Grupo 2 & Grupo 3 \\
\hline Pré-teste & 10 & 9,9 & 9,7 \\
Pós-teste & 10,4 & 10,6 & 15 \\
\hline
\end{tabular}


2 (controle) $(\mathrm{p}=0,8059)$. Isto indica que o simples contato com a tarefa não garantia uma maior compreensão postenior quando resolvendo a tarefa dos recipientes. $\mathrm{Na}$ realidade, a intervenção oferecida foi o fator determinante do desempenho no pós-teste.

O teste de Wilcoxon comparou o desempenho entre pré-teste e pós-teste em cada grupo. Como mostra a Tabela 2, não foram detectadas diferenças significativas entre o préteste e o pós-teste para as crianças do Grupo $1(p=0,7998)$ nem tampouco para as do Grupo 2 ( $\mathrm{p}=0,3454)$. Em contraste, as crianças do Grupo 3 (experimental) tiveram um desempenho significativamente melhorno pós-teste do que no pré-teste tanto no geral ( $\mathrm{p} \varangle, 001)$ com também em cada idade (Tabela 1).

Os resultados indicam que a intervenção teve um efeito positivo sobre o desempenho no pós-teste e que este efeito foi observado tanto no geral como em cada idade separadamente. Os demais grupos tiveram desempenho semelhante no pré e no pós-teste, isso significa que o passar do tempo (Grupo 2) e o simples contato com a tarefa (Grupo 1) não foram fatores que influenciassem 0 desempenho no pós-teste.

\section{As justificativas das crianças}

Justificativas são importantes em um estudo como este porque através delas é possível examinar se os julgamentos dotados eram ou não proporcionais e se a estratégia de 'metade' seria ou não adotada. Um total de 6480 justificativas foram analisadas (3240 no pré-teste e 3240 no pós-teste) e classificadas em três tipos, a partir de julgamentos independentes de dois juizes (nível de concordância de 90,46\%). Os casos de desacordo analisados por um terceiro juiz, também independente, que fomeceu a classificação final 3.

Justificativa 1 (não justifica ou fomece justificativas subjetivas). Exemplos: "Seinão”; “Porqueé”; “Porqueeu sei que éesee"; "Eupensinaminhacabeça”.

Justificativa 2 (justificativas não-proporcionais). 0 criténio adotado é a quantidade de água ou o nível da água nos recipientes. Exemplos:

“(...) neste a água está mais alta, então é o mais cheio.” (Item Tipo 1)

"Esse tá mais cheio porque tem mais água que o outro.É mais gordão aíleva mais água." (Item Tipo 2)

"Tá cheio os dois do mesmo jeito porque a quantidade de água é igual nos dois (aponta altura da água)." (Item Tipo 3)

"Esse tá maischeio (3/4) porque tem maiságua nele. Etambém porque tá mais alta a água nele. No de cá (1/4) a água tá baixa, fica pouca."(Item Tipo 4)
"Esse (3/4) tá mais cheio porque ele tá mais cheio de água. Tem muito mais água que o outro (1/4)." (Item Tipo 5) "Osdoistão igual de cheio. A água tána mesma linha (aponta altura) nos dois copos."(Item Tipo 6)

Justificativa 3 (justificativas proporcionais). A criança estabelece comparações entre o espaço vazio e o espaço ocupado pela água em cada recipiente e compara estas relacõos nos dois recipientes. Muitas vezes declara que ambos estão igualmente cheios, embora a quantidade de água não sejaa mesma nos dois recipientes; fazendo, assim, a diferença entre quantidade relativa e absoluta. As justificativas que faziam referência à 'metade' foram encontradas mais freqüentemente entre as crianças do Grupo 3 no pósteste. Exemplos:

"Aágua é diferente. Tem mais água aqui (copo longo) do que aqui (copo curto). Mas eles estão cheios do mesmo jeito porque eles têm metade are metade água." (Item Tipo 1)

“(... ) eles são a mesma coisa de cheio. Tá os dois cheio até 0 topo. Tão cheio do mesmo jeito." (Item Tipo 2)

"O copo pequeno támais cheio, eletáatéa boca. O outro tem metadeágua e metade de ar. Tá pouco cheio."(Item 3)

"Esse (3/4) tá mais cheio porque tem mais água que ar. No outro (1/4) tem mais arque água." (Item Tipo 4)

"Esse tá mais cheio (3/4) do que esse (1/4). Ele (3/4) tá quase no topo, tem mais água dentro do que tem de ar. O outro tem mais ardo que água dentro."(Item Tipo 5)

"A quantidade de água é mesma, eu acho. Mas este (1/2) tá maischeio porque ele tem metade de água e metade vazio; $\mathrm{e}$ o outro, coitadinho (1/4), tem muito espaço vazio e pouco espaço de água."(Item Tipo 6)

A freqüência de justificativas em cada grupo e em cada idade foram exploradas através do teste KolmogorovSmimov, sendo ilustrada na Tabela 3.

As crianças do Grupo 1 (tarefa) e do Grupo 2 (controle) produziam igualmente poucas justificativas proporcionais no pré-teste eno pós-teste. Entretanto, as crianças do Grupo 3 (experimental) fomeciam maisjustificativas proporcionais no pós-teste do que no pré-teste, como estatisticamente demonstrado pelo Kolmogorov-Smirnov (Grupo 3 vs. Grupo 1: $\mathrm{p} \ll 0,01$; e Grupo 3 vs. Grupo 2: $\mathrm{p}<0,01$ ).

Observa-se que, independentemente da idade, apenas as justificativas das crianças que receberam a intervenção (Grupo 3) se diferenciavam entre pré e pós-teste; isso ocorreu em relação às justificativas proporcionais (Justificativa 3). No Grupo 1 (tarefa) e no Grupo 2 (controle) havia um grande percentual de justificativas não proporcionais (Justificativa 2) tanto no pré como no pós-teste. A Tabela 4 apresenta a distribuição das justificativas em função dos grupos. 
Tabela 3

Porcentagem decada Tipodejusificativa

\begin{tabular}{|c|c|c|c|c|c|c|}
\hline & \multicolumn{6}{|c|}{ Grupo 1 (tarefa) } \\
\hline & \multicolumn{2}{|c|}{6 anos } & \multicolumn{2}{|c|}{7 anos } & \multicolumn{2}{|c|}{8 anos } \\
\hline & Pré-teste & Pós-teste & Pré-teste & Pós-teste & Pré-teste & Pós-teste \\
\hline I & 0,6 & 0,3 & 1,1 & 1,4 & 3,1 & $\overline{1,1}$ \\
\hline II & 84,7 & 85,0 & 77,2 & 66,7 & 87,2 & 86,1 \\
\hline \multirow[t]{2}{*}{ III } & 14,7 & 14,7 & 21,7 & 31,9 & 9,7 & 12,8 \\
\hline & \multicolumn{6}{|c|}{ Grupo 2 (controle) } \\
\hline I & 2,8 & 5 & 1,1 & 1,4 & 0,8 & 0,6 \\
\hline II & 84,7 & 83,3 & 91,4 & 87,5 & 85,6 & 73,3 \\
\hline \multirow[t]{2}{*}{ III } & 12,5 & 11,7 & 7,5 & 11,1 & 13,6 & 26,1 \\
\hline & \multicolumn{6}{|c|}{ Grupo 3 (expenimental) } \\
\hline I & 0,6 & 0 & 1,9 & 0,3 & 1,9 & 1,7 \\
\hline II & 89,4 & 45,3 & 86,7 & 35,5 & 75,3 & 33,3 \\
\hline III & 10 & 54,7 & 11,4 & 64,2 & 22,8 & 65,0 \\
\hline
\end{tabular}

Tabela 4

Porcentagem deJusificativasporGupoem cada OcasãodeTetagem

\begin{tabular}{crrrrrr} 
& \multicolumn{2}{c}{ Grupo 1 } & \multicolumn{2}{c}{ Grupo 2 } & \multicolumn{2}{c}{ Grupo 2 } \\
& Pré-teste & Pós-teste & Pré-teste & Pós-teste & Pré-teste & \multicolumn{1}{c}{ Pós-teste } \\
\hline I & 1,6 & 0,9 & 1,6 & 2,3 & 1,5 & 0,7 \\
II & 8,3 & 79,3 & 87,2 & 81,4 & 83,8 & 38,0 \\
III & 15,4 & 19,8 & 11,2 & 16,3 & 14,7 & 61,3 \\
\hline
\end{tabular}

Como observado, as justificativas não proporcionais do grupo expenimental diminuíram, passando de 83,8\% no préteste para $38 \%$ no pós-teste; enquanto as justificativas proporcionais aumentaram de 14,7\% para 61,3\%, respectivamente. Este dado indica que a intervenção propiciou o aparecimento de julgamentos proporcionais.

\section{Comparando as formas de raciocinar das crianças antes e após a intervenção}

De modo geral, antes da intervenção, o desempenho das crianças do grupo experimental foi semelhante àquele verificado no estudo original de Brunere Kenney (1966): elas consideravam apenas um atributo da situação (o espaço ocupado pela água) com base no nível ou no volume de água e estabeleciam comparações entre recipientes em termos absolutos, comparando a quantidade de água em cada recipiente. Para essas crianças 'mais cheio' significava ter um nível alto de água ou um maior volume de água; e 'igualmente cheio' significava terem os recipientes o mesmo nível ou o mesmo volume de água. Devido a isso, no pré-teste as crianças tinham dificuldades em reconhecera equivalência entre recipientes (itens Tipo 1 e Tipo 2), ou julgavam como equivalentes recipientes com água na mesma altura ou com o mesmo volume (itens Tipo 3 e Tipo 6).

Após a intervenção, as crianças tiveram, no pós-teste, um desempenho comparável ao das crianças mais velhas (10-11 anos) no estudo de Brunere Kenney (1966). Elas passaram a considerar os dois atributos relevantes da situação: o espaço cheio e o espaço vazio. Para essas crianças 'mais cheio' significava mais espaço ocupado com água do que espaço vazio, independentemente do nível de água e do volume de água; e 'igualmente cheio' significava ambos os recipientes terem a mesma relação espaço com água e espaço vazio.

As justificativas oferecidas no pós-teste evidenciam que as comparações entre recipientes eram feitas em termos relativos, comparando-se a água com o espaço vazio no interior de cada recipiente. Muitos desses julgamentos faziam menção ao referencial de metade. 
As crianças parecem ter superado a tendência em considerar o nível e o volume de água como criténios em seusjulgamentos, estabelecendo, então, a distinção cnucial entre quantidade absoluta e relativa. Por exemplo, elas não tiveram dificuldades com itens do Tipo 1, sendo capazes de reconhecera equivalência entre um recipiente grande cheio até a 'metade' e um recipiente pequeno cheio até a 'metade'. Esta é uma habilidade importante na construção do raciocínio proporcional e que não estava presente entre crianças mais novas no estudo de Brunere Kenney (1966).

\section{Discussão e Conclusão}

O resultado mais importante neste estudo foi que, independentemente da idade, as crianças que receberam a intervenção alcançaram um nível de compreensão sobre proporção mais elaborado do que as crianças dos outros dois grupos no pós-teste. Isto foi observado não apenas em relação ao número de acertos, mas também, em relação às justificativas proporcionais fomecidas. Apenas as crianças do grupo de intervenção tiveram progressos entre o pré-teste e o pós-teste, apesar do conhecimento inicial avaliado pelo pré-teste ter se mostrado semelhante em toda a amostra. A partir da consistência dos dados, concluiu-se que a intervenção teve um efeito bastante positivo na compreensão sobre proporção, compreensão esta avaliada em tarefa de proporção considerada complexa para crianças da faixa etária investigada.

Merece destaque o fato de que, após a intervenção, as crianças do grupo experimental superaram as dificuldades iniciais em estabelecer julgamentos proporcionais. Aspectos cruciais envolvidos no raciocínio proporcional foram encontrados nas justificativas após a intervenção, indicando que as crianças eram capazes de estabelecer comparações relativas ao invés de absolutas e de lidar com as relações de segunda-ordem. Por exemplo, após a instrução, elas reconheciam porestimativa, a equivalência entre recipientes apesar das diferenças quanto nível e ao volume absoluto de água, demonstrando, assim, capacidade de estabelecer a crucial distinção entre quantidade absoluta e relativa (proporção). As justificativas apresentadas após a intervenção mostram que as crianças estabeleciam relações de segunda-ordem com base no referencial de 'metade'. Este referencial mostrou-se, mais uma vez, seruma âncora importante para auxiliara criança a lidar com as quantidades e as relações em tarefas de proporção. Observou-se, ainda, que a estratégia de metade aprendida em uma dada situação foi transferida para outra situação análoga, porém não idêntica e mais complexa do que aquela em que fora explicitamente encorajada a seraplicada.

Em relação ao sucesso das crianças após a intervenção, toma-se importante considerar as seguintes questões: Isto significa que as crianças tinham alguma compreensão sobre proporção antes da intervenção, ou a intervenção ensinou sobre proporção pela primeira vez?É possível afirmar que as crianças chegaram à tarefa com alguma compreensão sobre proporção, como documentado por Spinillo e Bryant $(1991,1999)$ e que as intervenções do examinadoras encorajaram a adotar, de forma sistemática e explícita, uma estratégia que espontaneamente adotavam em outras tarefas de proporção. Em outras palavras, a instrução levou a criança a aplicar suas noções intuitivas a uma dada situação que usualmente não seria resolvida por esta estratégia, como mostram os resultados do estudo original de Brunere Kenney (1966) em que esta estratégia não era aplicada.

Se as crianças usam espontaneamente a estratégia de 'metade', como afirmado por Spinillo e Bryant, por que elas não adotaram esta estratégia na tarefa no préteste?Podese dizer que a tarefa dos recipientes não é de imediato percebida pelas crianças como uma situação em que possa ser aplicada esta estratégia na mesma extensão como o éa tarefa de Spinillo e Bryant. Entretanto, quando a estratégia de metade é sugenida, as crianças transferem o seu uso para a tarefa dos recipientes, adotando comparações parte-parte. O referencial de 'metade' facilita o estabelecimento de relações de primeira-ordem e o estabelecimento das de segunda-ordem, confirmando-se, assim, a hipótese levantada.

A importância das relações parte-parte não se restringe apenas ao conceito de proporção, como recentemente verificado por Jones, Langrall, Thomton e Mogill (1999) em um estudo que avaliou a eficácia de um programa instrucional em probabilidade com crianças de 10 anos de idade. Os resultados mostraram que níveis mais elaborados de raciocínio probabilístico eram alcançados após a intervenção. A progressão se caracterizava pelo uso inicial de raciocínio parte-parte apenas, e posteriomente, ao final dassessões deinstrução, pelo uso, de formaintegrada de esquema parte-parte e parte-todo. Considerando os dados no presente estudo e os de Jones e colaboradores (1999), é possível dizer que relações parte-parte fomecem a base para a criançalidarcom situações envolvendo conceitos relacionais diversos, como proporção e probabilidade.

Um comentário pode ser feito a respeito da aplicabilidade da estratégia de 'metade' em tarefas de proporção. A estratégia de 'metade' é efetiva para resolver muitas das tarefas de proporção encontradas na literatura, como, por exemplo, a tarefa do suco de laranja de 
Noelting (1980), a tarefa de quantificação de probabilidade de Piagete Inhelder(1975). Porém, há tarefas que não são resolvidas com sucesso através desta estratégia, como tarefas em que as dimensões são não-complementares como a balança de Piaget, as receitas de Hart (1981,1984), a tarefa do Sr. Altão de Karplus e Peterson (1979); ou que envolvem quantidades intensivas como velocidade, problemas de melhorcompra etc. Apesar dessas limitações, a estratégia de 'metade' desempenha papel importante na compreensão matemática inicial da criança, inclusive em relação a outros conceitos como a divisão (Parrat-Dayan \& Vonèche, 1992) e a fração (Lo \& Watanabe, 1997; Watanabe, Reynolds \& Lo, 1995).

A posição aqui apresentada está em acordo com duas abordagens sobre o desenvolvimento de conceitos matemáticos em crianças. Uma é aquela proposta porBryant (1974) sobre a importância das relações simples no desenvolvimento de conceitos matemáticos complexos. Essas relações simples são acionadas quando se introduz novos conceitos matemáticos, como demonstrado pela intervenção neste estudo. Maioratenção deveria ser dada a essas relações na resolução de tarefas de proporção. A outra abordagem é aquela proposta por Resnick e colaboradores (Resnick \& Singer, 1993; Singer, Kohn \& Resnick, 1997) sobre raciocínio protoquantitativo. Podese dizer que a estratégia de 'metade' é um julgamento protoquantitativo sobre situações envolvendo proporção e outros conceitos relacionais.

Os resultados deste estudo fornecem algumas implicações para o ensino de proporção. Pnimeiro, a instrução podenia iniciar-se mais cedo do que usualmente ocome (por volta dos 11-12 anos na 6 séne); segundo, deveria ocomer de maneira bem distinta da tradicionalmente adotada(através de cálculos numénicos e da aplicação do algonitmo da regrade-três), envolvendo situações-problema que fossem resolvidas através da estratégia de 'metade' e do uso de estimativas. Esta estratégia pode tomar-se um recurso didático poderoso para o ensino de proporção nas sénies iniciais; uma ferramenta que, inserida em um ambiente propício para discussões matemáticas, pemitiria enfatizar os aspectos cruciais ao raciocínio proporcional: a distinção entre quantidade absoluta e quantidade relativa, e as relações de primeira e de segunda-ordem.

De maneira mais ampla, as noções e estratégias intuitivas das crianças poderiam fazer parte das situações de ensino, visto serem elas importantes para a compreensão plena de conceitos matemáticos diversos, com enfatizado por muitos autores (Ex.: Hatano \& Susuki, 1992; Lamon, 1993; Lembke \& Reys, 1994; Spinillo, 1994a,1996; Streefland, 1982,1984, 1985). Fischbein (1987), por exemplo, afirma que a instrução escolar não deveria eliminar as representações intuitivas das crianças, ao contrário, deveria, a partir delas, construir novas representações consistentes com o conhecimento formal. A instrução, iniciando-se a partir da perspectiva cognitiva da criança podeniairalém, na direção de formas mais efetivas eabrangentes de raciocínio proporcional.

Seria relevante investigar se a intervenção conduzida individualmente neste estudo seria bem sucedida se conduzida no contexto de sala de aula. Uma investigação desta natureza podenia fomecerinfomações relevantes sobre o ensino e a aprendizagem de proporção nas sénies iniciais; utilizando como situações de aprendizagem muitas das situações até então utilizadas na pesquisa em psicologia cognitiva como recurso para avaliaras capacidades das crianças (artigo em preparação). Recentemente, Nunes, Campos, Magina e Bryant(2001), em obra voltada para o ensino de operações numénicas, tomam por base tarefas usadas em situações de pesquisa para gerar atividades de ensino no contexto escolar. Assim, transformaro presente estudo em uma expenência didática seria um ótimo exemplo para ilustrar as relações entre a psicologia cognitiva e a educação (ver Brito \& Garcia, 2001) e as relações entre aprendizagem e desenvolvimento (ver Spinillo, 1999).

\section{Referências}

Brito, M. R. F. de \& Garcia, V. J. M. (2001). A psicologia cognitiva e suas aplicações à educação. Em M. R. F. de Brito (Org.), Psicologia da educação matemática: Teoria epesquisa (pp.29-48). Flonanópolis, SC: Insular.

Bruner, J. S. \& Kenney, H. J. (1966). On relational concepts. Em J. S. Bruner, R. R. Olver \& P. H. Greenfield (Orgs.), Studies in cognitive growth (pp.168-182). New York, NY: John Willey.

Bryant, P.E (1974).Perception andunderstandingin youngchildren:An experimental approach. London: Methuen.

Correa, J., Spinillo, A. G., Brito, M. R. F. de \& Moro, M. L. F. (1998). O desenvolvimento de conceitos matemáticos: Temas de interesse para a educação matemática. Em M. L. Seidl de Moura, J. Correa \& A. G. Spinillo (Orgs.), Pesquisasbrasileirasem Psicologia do Desenvolvimento (pp. 73-110). Rio de Janeiro: EDUERJ.

Fischbein, E. (1987). Intuition in scienceand mathematics. Dordrecht, The Netherlands: Kluwer.

Hart, K. M. (1981). Ratio and proportions. Em K. M. Hart (Org.), Children's understanding of mathematics: 11-16 (pp. 88-101). London: Muray.

Hart, K. M. (1984). Ratios: Children'sstrategiesand errors. Windsor: NFER-Nelson.

Hatano, G. \& Susuki, H. (1992, Agosto). Transferringchildren'sinformalknowledge to classroom problem solvingsituation by creatingpragmatic context. Trabalho apresentado na $25^{\text {th }}$ International Conference of Psychology, Brussels, Belgium.

Inhelder, B. \& Piaget, J. (1976). Da lógica da criança à lógica do adolescente. São Paulo: Pioneira.

Jones, G. A., Langrall, C. W., Thomton, C. A. \& Mogill, A. T. (1999). Students'probabilistic thinking in instruction. Journal for Research in MathematicsEducation, 30, 487-519.

Karplus, R. \& Peterson, R. W. (1970). Intellectual development beyond elementary school II: Ratio, a survey. School-Scienceand Education, 70(9), 813-820 
Lamon, S. J. (1993). Ratio and proportion: Connecting content and children's thinking. Journal for Research in MatematicsEducation, 24, 41-61.

Lembke, L. O. \& Reys, B. J. (1994). The development of, and interaction between, intuitive and school-taught ideas about percent. Journal for Research in MathematicsEducation, 25(3), 237-259.

Lo, J-J. \& Watanabe, T. (1997). Developing ratio and proportion schemes: A story of a fifth grader. Journal for Research in Mathematics Education, 28(2), 216-236.

Müller, D. J. (1978). Children's concepts of proportion: An investigation into the claims of Bryant and Piaget. British Journal of Educational Psychology, 48, 29-35

Müller, D. J. (1979). Perceptual reasoning and proportion. Mathematics Teaching, 87, 20-22.

Noelting, R. (1980a). The development of proportional reasoning and the ratio concept Part I - Differentiation of stages. Educational Studies in Mathematics, 11, 217-253.

Noelting, R. (1980b). The development of proportional reasoning and the ratio concept Part II - Problem structure at successive stages: Problem-solving strategies and the mechanism of adaptative restructuring. Educational Studiesin Mathematics, 11, 331-363.

Nunes, T., Campos, T. M. M., Magina, S. \& Bryant, P. (2001). Introdução à educaçãomatemática. Osnúmeroseasoperaçõesnuméricas São Paulo:PROEM.

Parrat-Dayan, S. \& Vonèche, J. (1992). Conservation and the notion of 'half'. Em J. Bideaud, C. Meljac \& J-P. Fischer (Orgs.), Pathways to number: Children'sdeveloping numerical abilities(pp.67-82). Hillsdale, NJ: Erlbaum.

Piaget, J. \& Inhelder, B. (1951/1975). Theorigin of theidea of chancein children. New York, NY: Norton.

Resnick, LB. \& Singer, J.A. (1993). Protoquantitative origins of ratio reasoning. Em T.P. Carpenter; E. Fennema \& T.A. Romberg (Orgs.), Rational numbers: An integration of research (pp. 107-130). Hillsdale, NJ: Erlbaum.

Siegler, R.S. \& Vago, S. (1978). The development of proportionality concept: Judging relative fullness. Journal of Experimental Child Psychology, 25, 371-395.

Singer, J. A., Kohn, A. S. \& Resnick, L B. (1997). Knowing about proportions in different contexts. Em T. Nunes \& P. Bryant (Orgs.), Learning and teachingmathematics: An international perspective(pp. 115-132 ). Hove: Psychology Press.

Singer, J. \& Resnick, L B. (1992). Representations of proportional relationships: Are children part- part or part-whole reasoners? Educational Sudiesin Mathematics, 23, 231-246.

Spinillo, A. G. (1992). A importância do referencial de 'metade' e o desenvolvimento do conceito de proporção. Psicologia:Teoria ePesquisa, 8(3), 305-317.

Spinillo, A. G. (1993). As relações de primeira-ordem em tarefas de proporção: Uma outra explicação quanto às dificuldades das crianças. Psicologia: Teoria ePesquisa, 2(9), 349-364.

Spinillo, A. G. (1994a). O conhecimento matemático de crianças antes da matemática na escola. A Educação Matemática em Revista, 2(3), 41-50.
Spinillo, A. G. (1994b). Raciocínio proporcional em crianças: Considerações acerca de altemativas educacionais. Revista Pro-Posições, 5(1), 109-114.

Spinillo, A. G. (1996). Developmental perspectives on children's understanding of ratio and proportion and the teaching of mathematics in primary school. Em J. Giménez, R.C. Lins \& B. Gómez (Orgs.), Arithmeticsand algebra education: Searching for thefuture(pp. 132-137). Barcelona: Copisteria Asturias.

Spinillo, A. G. (1997a). Chance estimates by young children: Strategies used in an ordening chance task. Trabalho apresentado na $21^{\star}$ Conference of theInternational Group for thePsychology of MathematicsEducation (Vol. 4, pp. 182-189). Lahti, Finland.

Spinillo, A. G. (1997b). Proporções nas séries iniciais do primeiro grau. Em A.D. Schliemann; D. W. Carraher, A. G. Spinillo, L L Meira, J. T. R. Falcão \& N. Acioly-Regnier (Orgs.), Estudosem psicologia da educação matemática (pp. 40-61) ( $2^{\mathrm{a}}$ ed). Recife: Editora da UFPE.

Spinillo, A. G. (1999). As relações entre aprendizagem e desenvolvimento discutidas a partir de pesquisas de intervenção. Arquivos Brasileiros de Psicologia, 51(1), 55-74.

Spinillo, A. G. \& Bryant, P. E. (1991). Children's proportional judgements: The importance of half'. Child Development, 62, 427-440.

Spinillo, A. G. \& Bryant, P. (1999). Proportional reasoning in young children: Part-part comparisons about continuous and discontinuous quantities. Mathematical Cognition, 5(2), 181-197.

Streefland, L. (1982). The role of rough estimation in learning ratio and proportion. An exploratory research [Resumos]. Em International Group for the Psychology of Matematics Education (Org.), trabalho apresentadona 6th Intemational Conferencefor thePsychology of Mathematics Education (Vol. 2, pp.193-199). Antwerp, Holland.: PME.

Streefland, L (1984). Search for the roots of ratio: Some thoughts on the long term learning process (Towards...a theory). Part I: Reflections on a teaching experiment. Educational Sudiesin Mathematics, 15, 327348.

Streefland, L (1985). Search for the roots of ratio: Some thoughts on the long term learning process (Towards...a theory). Part II: The outline of the long term leaming process. Educational Studiesin Mathematics, $16,75-94$.

Tourniaire, F. \& Pulos, S. (1985). Proportions in elementary school: Educational Studiesin Mathematics, 16, 181-204.

Watanabe, T., Reynolds, A. \& Lo, J. J. (1995). A fifth grader's understanding of fractions and proportions [Resumos]. Em International Group for the Psycology of Mathematics Education (Org.), Trabalho apresentado na 19th Conference of theIntemational Groupfor thePsychology of Mathematics Education (Vol.3, pp. 200-207). Recife, Brasil: PME.

Recebido: $21 / 10 / 2001$

1' Revisão: 05/12/2001

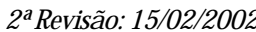

3a Revisão: 10/04/2002

Aceite Final: 16/04/2002

Sobre a autora

Alina Galvão Spinillo é Doutora em Psicologia pela Universidade de Oxford (Inglaterra), é PosDoutora pela Universidade de Sussex (Inglatema). Pesquisadora e ProfessoraAdjunta IV do Programa de Pós-Graduação em Psicologia Cognitiva da Universidade Federal de Pemambuco. 